Journal of English Language Teaching

UNNES

http://journal.unnes.ac.id/sju/index.php/elt

\title{
Potential Relationship between Self-Efficacy Beliefs and Proficiency in Grammar among Tertiary EFL Learners
}

\section{Achmad Kholili ${ }^{凶}$}

Institut Ilmu Keislaman Zainul Hasan Genggong, Probolinggo, Indonesia

\section{Article Info \\ Article History: \\ Received in 21 April \\ 2020 \\ Approved in 1 July 2020 \\ Published in 30 July \\ 2020 \\ Keywords: Self-efficacy; \\ English; grammar}

\begin{abstract}
A multitude of studies on self-efficacy beliefs have been undertaken to date, especially in language learning. However, little evidence is given on looking into the relationship between self-efficacy and English grammar. To this end, the present study goes about identifying to what extent the correlation between learners' self-efficacy and their achievements in the grammar test is. Drawing on the correlational design, an English grammar test was administered to the learners to know the learners' acquaintance with the English grammar. Meanwhile, a self-efficacy questionnaire was performed by the researcher to the learners to figure out to what extent their efficaciousness is. A Pearson-product moment correlation was performed to analyze the relationship between such variables. The result demonstrates that there is a high positive significant correlation between learners' self-efficacy and their attainments in the grammar test, displayed by $r$ Correlation $=+1$. This finding brings a recent insight in the field of language learning.
\end{abstract}

(C) 2020 Universitas Negeri Semarang

Correspondent Address:

p-ISSN 2252-6706 | e-ISSN 2721-4532

Department of English, Faculty of Tarbiyah

Kraksaan, Probolinggo, East Java, Indonesia, 67282

E-mail:achmadkholili93@gmail.com 


\section{INTRODUCTION}

Notable success from learners is, among other things, considerably influenced by their beliefs in themselves, including the achievements in academic settings. A set of the beliefs is strengthened and combined with their ability to cope with something they are dealing with. In this regard, this perceived beliefs are summoned as selfefficacy, referring to the beliefs one has about their ability to perform a task or behavior (Bandura, 1997). This puts strong emphasis on the way a person should address the problems, including how people or learners overcome their difficulties in learning English, one of which is grammar.

To date, a mass of evidence has emerged that self-efficacy has a dramatic impact on one's achievement. This has been accounted for by numerous studies carried out by some researchers. First, a study was undertaken by Bai et al. (2018). They conducted a study on the relationship between social supports, self-efficacy, and English language achievement in Hong Kong. Employing a correlational study, (Bai et al., 2018) found that social supports (teachers, parents, and peers), self-efficacy, and English learning achievement are closely related to each other from the weak to moderate strengths.

Looking back to several years ago, the co-relational study was also ever made by (Wang, 2005). He examined the relationship between language learning strategies and language self-efficacy. Seventy-four graduate ESL pre-service teachers (13 males, 61 females) of a teacher's college in Kuching, Sarawak, Malaysia took part in this study. By distributing self-efficacy questionnaire and interview, the finding demonstrated that there is a positive correlation between language strategies and language self-efficacy. The high self- efficacy of the pre-service teachers reported more frequent use of more number of language learning strategies than did low self-efficacy pre-service teachers.

Quite recent research was also carried out by (Ivars et al., 2014), especially on the correlation between self-efficacy and language proficiency in interpreter trainees. Drawing upon the sample of 281 participants enrolled as the final year students in the translation and interpretation degree program at University of Jaume I, Spain, over three consecutive academic years-i.e. approximately 90 subjects per year, all of the students, obtained the same training in interpreting-approximately 160 contact hours ranging from 18-24 in age. The findings of his study exhibit that self-efficacy relevant when predicting performance only in trainees with high linguistic competence. However, high linguistic competence trainees lacking self-efficacy offered poorer interpretation renderings.

While a bulk of former studies on self-efficacy have been done by the researchers, there is a paucity of the study on the relationship between self-efficacy and the grammar performance. To this effect, the researcher devotes his full attention to the correlation between learners' perceived self-efficacy and performances in the grammar test. This study is aimed at examining whether or not there is a correlation between both of the variables.

\section{LITERATURE REVIEW}

\section{Self-effiacy}

Self-efficacy has been defined as one's beliefs about one's ability to perform a task or behavior (Bandura, 1997). In this regards, the belief becomes a critical factor detemining one's success, say, in academic settings. Therefore, the performance of the task may differ markedly depending on the belief of their efficacy in that task (Bandura, 1997, 1986, 1997) cited in (Sala\& Redford, 2012). Furthermore, Magowwe \& Oliver (2007) notes that this selfefficacy may mediate the effects of other influences, including aptitude, previous achievement, or subsequent achievement. Bandura (2010) further emphasizes that the stronger the perceived self-efficacy, the higher the objective challenges ones set for themselves and the stronger is their commitment to them (Bandura,2010). Accordingly, this factor has a huge impact on how people accomplish their goals.

This self-efficacy indeed contributes significantly to the ways people lead to their success. The scenario they set to achieve the goal may be enormously affected by self-efficacy they construct in themselves; and therefore, those who have a high sense of efficacy visualize success of scenario that gives positive guides and supports for performance. On the other hand, those who doubt their efficacy portray failure scenario and dwell on the many things that can go wrong. As a result, it is difficult to achieve much while fighting self-doubt (Bandura, 2010).

\section{Grammar}

Grammar which has been continuously studied by both EFL and ESL Learners still becomes problematic for learners in particular. While the methods and approaches have been executed, the learners still grapple with some complexities, such as tenses, adjective clauses, the use of preposition, conjunction usage, and etc in constructing a sentence. Greenbaum \& Nelson (2013) note that grammar is set of rules which allow us to combine words in English into larger units. 
Grammar, however, is still deemed as a complex rule which makes EFL learners fail to achieve success in studying it. For instance, the use singular and plural may be different each other in terms of combining it with verbs in the sentence. A case in point is that the verb used in a sentence is "come", and when it is used in a sentence, it will definitely be relied on what the subject the one uses. If the subject is I, then the sentence becomes 'I come', and may slightly differ from the sentence employing a singular form, say, "He", then it will become "He comes". This complexity makes some EFL learners bored in learning English grammar. As a consequence, they fail to achieve good in English, as has been stated by Rimmer (2006) that difficulties of grammar can be found in the form and structure.

\section{METHODS}

This study draws on the correlational research for which participants, data collection, and data analysis are accounted in the following. The correlational research, in this case, was carried out to examine the relationship between the students' perceived self-efficacy and their performance in the grammar test.

\section{Participants}

The study elicited 30 English major Students from Univeristy of Islam Zainul Hasan Genggong, Probolinggo, East Java, Indonesia. The learners were taken out with the simple random sampling. At first, all of the learners majoring in English Department at the University were 60 students: 30 in class A and 30 in class B. However, the researcher subsequently selected one of them randomly as the sample of this study and it was found class A to be the sparticipants. To this end, 30 learners in class A voted for their efficacies and accomplished the grammar test.

\section{Data Collection}

The researcher sought to gather the data by delivering a general self-efficacy questionnaire and the grammar test to the learners. The general self-efficacy questionnaire was used to investigate their beliefs of their ability to complete a task, and the grammar test was used to know their knowledge of grammar. There were 10 questions in the grammar in which all are in the form of multiple choice tests taken from (http://esl.fis.edu/grammar/q $7 \mathrm{~m} / 1 . \mathrm{htm}$ ), whereas 10 statements of the general self-efficacy questionnaire adopted from Jerusalem \& Schwarzer (1995) were distributed to the students, determining to what extent the learners' efficacies towards the grammar test. The data were garnered after the students studied a TEFL in their class in which it occurred approximately at $11 \mathrm{a} . \mathrm{m}$. in the daylight. During the time, the learners began completing the self-efficacy questionnaire and the grammar test.

\section{Data Analysis}

After the data were gathered, the researcher subsequently calculated the data by counting up the results revealed by the students in the self-efficacy questionnaire and in the grammar test. It was counted up based on to what extent their self-efficacies were and how many students received the correct answers from the grammar test. A person-product moment correlation was afterwards performed to identify the relationship between the selfefficacy and their grammar performance. Therefore, the hypotheses are formulated in the following. There are two hypotheses proposed in this study, namely the Alternative Hypothesis and Null Hypothesis:

1. H1 (Alternative Hypothesis): there is a significant correlation between learners' perceived self-efficacy and their grammar performance.

2. H0 (Null Hypothesis): there is no significant correlation between learners' perceived self-efficacy and their grammar performanc

Following that, the formula for person-product moment correlation is presented in the following:

Where:

$$
r x y=\frac{n \sum X Y-\left(\sum X\right)\left(\sum Y\right)}{\sqrt{\left\{n \sum X^{2}-\left(\sum X\right)^{2}\right\}\left\{n \sum Y^{2}-\left(\sum Y\right)^{2}\right\}}}
$$

\section{rxy : Pearson r correlation coefficient \\ $n \quad:$ Numbers of samples \\ $x \quad$ : Independent variables \\ $y \quad$ : Dependent variables}

Meanwhile, the formula for calculating the results of the grammar test is presented in the following: 


\section{GRAMAR TEST}

$$
\mathrm{N}=\frac{Y}{n} x 100
$$

Where:

$Y \quad:$ The result of the correct answers

$N \quad$ : The total number of answers

\section{FINDING AND DISCUSSION}

The finding of this study demonstrated that self-efficacy has a remarkable correlation with the performances in grammar. This finding indeed reports a straightforward fact that learners' efficaciousness confirms a definite prediction in terms of how learners notch up their success in completing the grammar quiz. The following is the r Calculation result. In this case, the two variables are correlated using a Person Product moment correlation.

\begin{tabular}{llllll}
\hline NO & $\mathbf{X}$ & $\mathbf{Y}$ & $\mathbf{X} 2$ & Y2 & $\mathbf{X Y}$ \\
\hline 1 & 37 & 70 & 1369 & 4900 & 2590 \\
2 & 40 & 80 & 1600 & 6400 & 3200 \\
3 & 38 & 85 & 1444 & 7225 & 3230 \\
4 & 40 & 95 & 1600 & 9025 & 3800 \\
5 & 36 & 75 & 1296 & 5625 & 2700 \\
6 & 40 & 95 & 1600 & 9025 & 3800 \\
7 & 38 & 80 & 1444 & 6400 & 3040 \\
8 & 37 & 90 & 1369 & 8100 & 3330 \\
9 & 29 & 50 & 841 & 2500 & 1450 \\
10 & 34 & 65 & 1156 & 4225 & 2210 \\
11 & 31 & 45 & 961 & 2025 & 1395 \\
12 & 35 & 70 & 1225 & 4900 & 2450 \\
13 & 32 & 50 & 1024 & 2500 & 1600 \\
14 & 33 & 60 & 1089 & 3600 & 1980 \\
15 & 39 & 90 & 1521 & 8100 & 3510 \\
16 & 15 & 60 & 225 & 900 & 450 \\
17 & 27 & 50 & 729 & 2500 & 1350 \\
18 & 30 & 60 & 900 & 3600 & 1800 \\
19 & 32 & 60 & 900 & 3600 & 1920 \\
20 & 38 & 75 & 1444 & 5625 & 2850 \\
21 & 40 & 85 & 1600 & 7225 & 3400 \\
22 & 38 & 80 & 1444 & 6400 & 3040 \\
23 & 18 & 45 & 324 & 2025 & 810 \\
24 & 37 & 80 & 1369 & 6400 & 2960 \\
25 & 40 & 95 & 1600 & 9025 & 3800 \\
26 & 39 & 75 & 1521 & 5625 & 2925 \\
27 & 35 & 80 & 1225 & 6400 & 2800 \\
28 & 40 & 80 & 1600 & 6400 & 3200 \\
29 & 23 & 20 & 529 & 400 & 460 \\
30 & 28 & 65 & 784 & 4225 & 1820 \\
Total & 1019 & 2080 & 35.857 & 154.900 & 173.870 \\
\hline & & & & &
\end{tabular}

They were then calculated using the formula of person-product moment correlation as follows: 


$$
\begin{aligned}
& r x y=\frac{n \sum X Y-\left(\sum X\right)\left(\sum Y\right)}{\sqrt{\left\{n \sum X^{2}-\left(\sum X\right)^{2}\right\}\left\{n \sum Y^{2}-\left(\sum Y\right)^{2}\right\}}} \\
& r x y=\frac{(30.73870)-(1019)(2080)}{\sqrt{\left\{30.3585-(1019)^{2}\right\}\left\{30.154900-(2080)^{2}\right\}}} \\
& r x y=\frac{2.216 .100-2.119 .520}{\sqrt{\{1.075 .710-1.038 .361\}\{4.647 .000-4.326 .400\}}} \\
& r x y=\frac{96.580}{\sqrt{\{37.349\}\{320.600\}}} \\
& r x y=\frac{96.580}{\sqrt{11.974 .089 .400}} \\
& r x y=\frac{96.580}{109,42} \\
& r x y=882,65
\end{aligned}
$$

\section{Notes:}

\begin{tabular}{lll}
\hline \multicolumn{2}{l}{ The Degree of Freedom } \\
\hline $\mathrm{r}$ Table & $\mathrm{r}$ Calculation & Correlation \\
0.361 & 882.65 & Significant \\
\hline
\end{tabular}

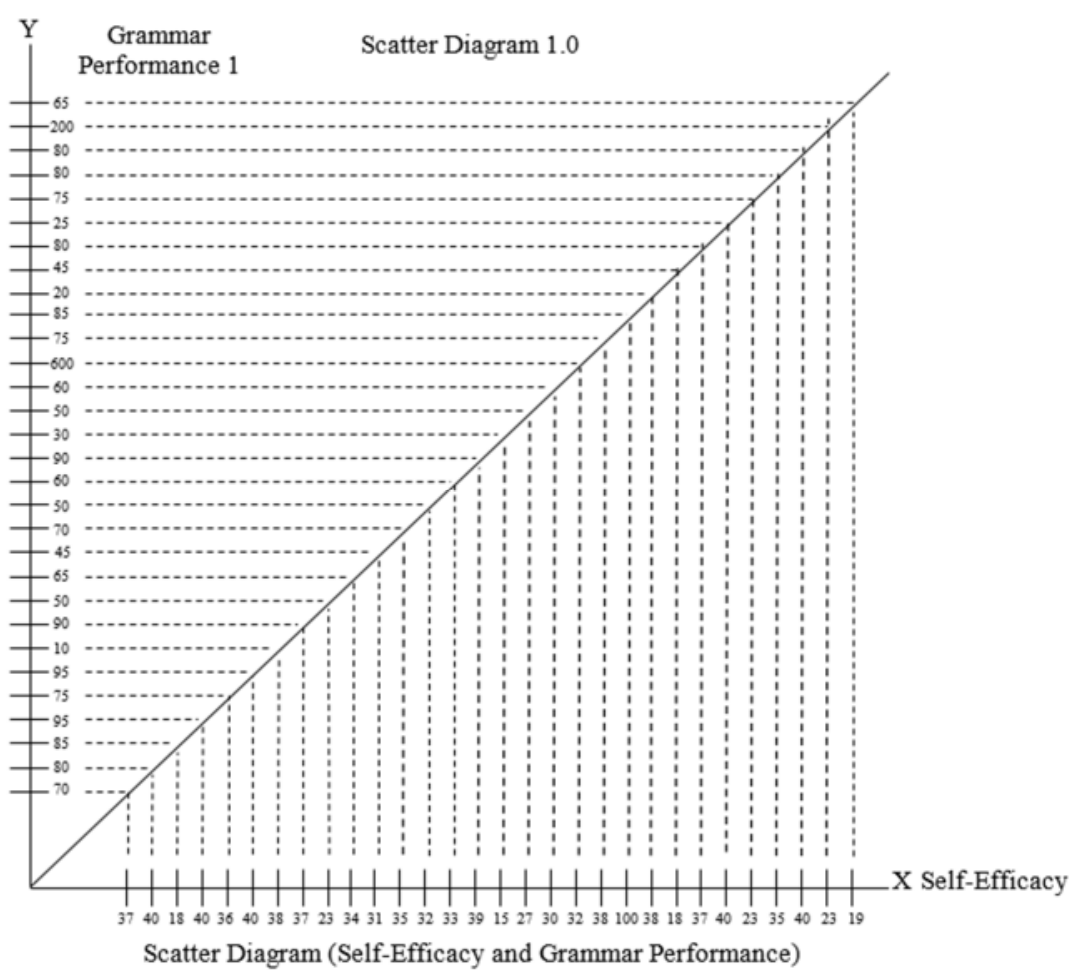

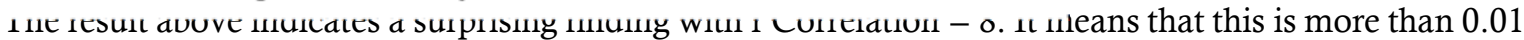
or $>1$ and is therefore categorized as the highest positive significant correlation between learners' perceived self- 
efficacy and their proficiency in grammar. Therefore, H1 is accepted and H0 is clearly rejected. In brief, the higher the students' self-efficacy they have, the better they perform in a certain task or behavior.

\section{Discussion}

The present study is predicated on the idea that successful language learners, including in grammar performances are, among other things, by dint of beliefs and cognitive factors, such as self-efficacy. The students, in this case, was required of completing both the general self-efficacy questionnaire and the grammar test to identify the extent to which the relationship between self-efficacy and learners' performances in grammar. What follows is a quick view on the relationship between both of the variables.

Along with the research questions addressed in the former chapter, that is, is there a significant correlation between learners' perceived self-efficacy and performances in grammar? The findings have come up with the full attention that self-efficacy is significantly correlated with the academic performances, particularly in grammar, with the view of (r): 0.80 , categorized as high significant correlation. The learners with high selfefficacy could pass the test well, reflected by their marks on the subject, ranging from 70, 80 up to 100 . Those with high self-efficacy attained the grammar test between 80 and 100 on average, whereas those who have low self-efficacy got hold of 30 and 50 evenly. Those with high self-efficacy believe firmly in the grammar test that they could perform correctly in grammar rather than those with the low ones. As has been claimed by Schunk \& Pajares (2010) that self-efficacy beliefs heighten human accomplishment and well-being in countless ways. They affect the choices people make and the courses of action they pursue.

The finding carries a profound implication that learners should have high self-efficacy in learning to reach a satisfying result, including English grammar. Bandura and his colleagues have undertaken an experiment on the power of self-efficacy and found that this variable has a considerable impact on students' level of performance, task choice, effort, persistence, thought patterns, and stress reactions (Bandura, 1986), cited in (Word \& Locke, 1987).

This self-efficacy becomes a key determinant in academic success, including the success of learning English grammar as has been depicted in the finding earlier. Beliefs and confidence in copying with particular task or exhibiting a behavior may significantly come to fruition. It encompasses the academic success in college. No matter what the tests are, self-efficacy factor enormously predisposes learners to their levels of performance in the academic settings. Chemers, Hu, and Garcia, (2001) affirmatively argue that it must be acknowledged that high school GPA itself is closely correlated to academic self-efficacy and that high school performance is likely to have been affected by the levels of academic self-efficacy that existed at the time. Furthermore, Bouffard - Bouchard, Parent, and Larivee (1991) also claim that those self-efficacies wield great influence on various aspects, such as self-regulation, task persistence, and performance

Further studies in terms of self-efficacy are strongly suggested. The ensuing researcher may carry out a study on other dimensions, such as on TOEFL test, placement test, and several similar teststhat can be administered using larger samples in different spots.

\section{CONCLUSION}

The findings of this study stress the importance of drawing on self-efficacy in English learning, for instance, grammar as stated above. The students, above, with high self-efficacy engender greater confidence than those who are not. Those categorized as highly efficacious learners gained better in the grammar test than those with the low ones. This definitely proves that self-efficacy contributes heavily to the achievement.. In brief, the higher the students'self-efficacy the learners have, the better they perform in the grammar test.

\section{Notes on the Contributor:}

Achmad Kholili is an English Lecturer at the Universitas Islam Zainul Zainul Hasan Genggong, Probolinggo, Indonesia. Formerly, he has published his research articles in International Journal of Research in English Education, LINGUAL: Journal of Language and Culture, and VELES: Voice of English Language Education Society. His research interests fall within the area of ELT and Applied Linguistics.

\section{REFERENCES}

Bai, B., Chao, G.C.N., \& Wang, C. (2018).The Relationship between Social Supports, Self Efficacy and English Langauge Learning Achievement in Hong Kong. TESOL Quarterly, O(0), 245-269.

Bandura, A. (2010). Perceived Self-Efficacy in Cognitive Development and Functioning.Educational Psychologist, 28(2), 117-148.

Bouffard-Bouchard, T., Parent, S., \&Larivee, S. (1991). Influence of Self-Efficacy on Self Regulation and Perfromance among Junior and High School Age Students.International Journal of Behaviorial Development, 14(2), 153-164. 
Chemers, M.M. Hu, L. \& Garcia, B.F. (2001).Academic Self-Efficacy and First Year College student performance and adjustment.Journal of Educational Psychology, 93(1), 55-64.

Greenbaum, S., \& Nelson, G. (2013).An Introduction to English Grammar(3rd Ed.). New York: Routledge.

Ivars, A.J., Catalyud, D.P. \&Fores, M.R.I. (2014).Self-efficacy and Langauge Proficiency in Interpreter Trainees.The interpreter and Translator Trainer, 8(2), 167-182.

Magogwe, J.M. \& Oliver, R. (2007). The Relationship between language learning strategies, proficiency, age, and self-efficacy beliefs: A study of language learners in Botswana. System, 35, 338-352.

Pre-Sala, M. \& Redford, P. (2012). Writing Essays: Does self Efficacy matters? The relationship between self efficacy in reading and in writing and undergraduate students' performance in essay writing.Educational Psychology, 32(1), 9-20.

Rimmer, W. (2006). Measuring Grammatical Complexity: the Gordanian knot. Language Testing, 23(4), 497519 .

Schunk, D.H. \&Pajares, F. (2010).Self Efficacy Beliefs.In Elsevier Ltd.

Schwarzer, R. \& Jerusalem, M. (1995). Generalized Self Efficacy Scale. In J.Weinmen, S. Wright, \& M.Johnston. Measures in Health Psychology: A user's portfolio. Causal and Control Belifes (pp. 35-37). Windsor, UK: NFEER-NELSON.

Wong, M.S.L. (2005). Language Learning Strategies and Language Self-Efficacy: Investigating the relationship in Malaysia. RELC Journal, 36(3), 245-269.

Wood, R.E. \& Locke, E.A. (1987).The relation of Self-Efficacy and Grade goals to Academic Performances. Educational and Psychological Measurement, 1(47), 1013-1024. 